\title{
Management of hypercholesterolemia, appropriateness of therapeutic approaches and new drugs in patients with high cardiovascular risk
}

\author{
Roberto Vettor, Roberto Serra \\ Internal Medicine 3, Endocrine-Metabolic Laboratory, Department of Medicine DIMED, University of Padova, Padova, Italy
}

\begin{abstract}
Hypercholesterolemia is a major risk factor for cardiovascular disease (CVD). Lowering low-density lipoproteins-cholesterol (LDL-C) has been shown to decrease the risk of CVD and of all-cause mortality. For appropriate management, estimation of each individual's total cardiovascular risk is critical, as patients should receive treatment according to their cardiovascular risk category as well as their LDL-C level. However, available data indicate that a large proportion of patients fail to achieve lipid goals despite treatment, and a significant percentage of patients are not able to tolerate statin treatment. Researchers have therefore focused considerable attention on the development of novel LDL-C-lowering agents that act via different mechanisms. Among the most recent advances in clinical development are the proprotein convertase subtilisin/kexin 9 antibody inhibitors, including alirocumab and evolocumab, which appear particularly promising, with clinical trial data indicating these agents to be both well tolerated and highly efficacious in lowering LDL-C.
\end{abstract}

\section{Introduction}

Hypercholesterolemia and elevated plasmatic levels of low-density lipoproteins-cholesterol (LDLC) - are major risk factors for cardiovascular disease (CVD) - the leading cause of death worldwide. ${ }^{1}$ While hypercholesterolemia is asymptomatic, it can lead to atherosclerosis, stenosis of blood vessels and eventual clinical vascular disease. Importantly, there is a strong graded association between elevated total plasma

Correspondence: Roberto Vettor, Internal Medicine 3, Endocrine-Metabolic Laboratory, Department of Medicine DIMED, University of Padova, via Giustiniani 2, 35100 Padova, Italy. Tel.: +39.0498.213333 - Fax: +39.0498.213332.

E-mail: roberto.vettor@unipd.it

Key words: Cardiovascular prevention; drug therapy; hypercholesterolemia; lipid lowering therapy; cardiometabolic disease.

Contributions: the authors contributed equally.

Conflict of interest: the authors declare no potential conflicts of interest.

Received for publication: 27 June 2018.

Accepted for publication: 3 July 2018.

This work is licensed under a Creative Commons Attribution NonCommercial 4.0 License (CC BY-NC 4.0).

CC Copyright R. Vettor and R. Serra, 2018

Licensee PAGEPress, Italy

Italian Journal of Medicine 2018; 12:203-212

doi:10.4081/itjm.2018.1062 cholesterol and LDL-C levels and increased cardiovascular risk in those with and without existing CVD. ${ }^{1}$

Hypercholesterolemia can be primary, i.e. due to an inherited disease [familial hypercholesterolemia $(\mathrm{FH})$ ] with several genes contributing to increased LDL-C levels, ${ }^{2}$ or it can be secondary to other diseases, such as obesity, diabetes, alcohol abuse, unbalanced nutrition, Cushing's syndrome, hepatic and renal disease, ${ }^{3}$ and drug related, including corticosteroids, isotretinoin and etretinate, and cyclosporine. ${ }^{1}$

Familial (hyperlipoproteinemia type IIa) hypercholesterolemia comprises heterozygous $\mathrm{FH}$ $(\mathrm{HeFH})$, which has been attributed to a heterozygous variant in one of three genes ( $L D L R, A P O B, P C S K$ 9), accounting for $70-95 \%$ of $\mathrm{FH}$, and homozygous $\mathrm{FH}$ $(\mathrm{HoFH}),{ }^{4}$ caused by either two mutations in one of these known genes or one mutation in each of two different genes.

Lowering LDL-C has been shown to decrease the risk of CVD and of all-cause mortality. ${ }^{1}$ However, while the evidence pointing to the importance of reducing LDL-C levels to reduce cardiovascular morbidity and mortality is unequivocal, a high proportion of patients are statin-intolerant ${ }^{5}$ and/or refractory. In patients who are inadequately treated, or who respond poorly to treatment, there is increased cardiovascular risk and suboptimal CVD prevention. ${ }^{1}$ Here we review current management of hypercholesterolemia, the appropriateness of existing therapeutic approaches and the need for novel drugs in patients with high cardiovascular risk. 


\section{Methods of research}

This narrative review comprised an automated literature search strategy and manual selection using PubMed, with no date or other limits. Search terms used were 'hypercholesterolaemia/-emia', 'treatment/ therapy/drug', 'high cardiovascular/cardiovascular risk', with further manual searches performed to find papers relating to treatments for patients who do not respond adequately to statin therapy or do not achieve LDL-C targets on statins. Specific drug searches were performed using these general terms AND 'alirocumab', 'evolocumab', 'lomitapide' OR 'mipomersen', with manual searches performed to find relevant treatment guidelines. Other papers were provided by the authors from their own libraries or were selected from the bibliographies of articles found in the automated search.

\section{Cardiovascular risk}

Estimation of a patient's total cardiovascular risk is critical for the appropriate management of each individual patient. ${ }^{6}$ There are certain factors known to place patients at high risk of cardiovascular events, including very high LDL-C. ${ }^{1}$ Risk assessment should include assessment of traditional atherosclerotic risk factors: age, sex, total and high-density lipoproteinscholesterol (HDL-C), systolic blood pressure, use of antihypertensive therapy, diabetes, and current smoking status, ${ }^{7}$ and a risk estimation, such as the Systematic Coronary Risk Evaluation Project (SCORE) system, should be used. The SCORE system provides an assessment of 10-year risk of a first fatal atherosclerotic event, including heart attack, stroke, aneurysm of the aorta, and sudden cardiac death. ${ }^{1,8}$ The method of assessing total risk allows for risk reduction strategies from multiple angles, if one risk factor cannot be adequately addressed, risk can still be reduced by focusing on other factors. ${ }^{1}$

\section{Standard management}

Patients should receive treatment according to their cardiovascular risk category and LDL-C level: ${ }^{9}$ the first priority should be LDL-C lowering with statins with or without other lipid-modifying therapies (LMTs), to lipid targets defined according to the SCORE risk categories. However, there should also be emphasis on lifestyle modifications. Modulation of absolute risk with a combination of lifestyle changes and control of LDL-C hypercholesterolemia, especially in those with diabetes/metabolic syndrome, is of the utmost importance. The most significant reduction in cardiovascular risk is achieved through
LDL-C reduction with statin therapy, and while other LMTs (fibrate, niacin, or ezetimibe) are adjunctive therapies, clinical trials data do not show the same degree of cardiovascular risk reduction, compared with statins, when used as monotherapy. ${ }^{9}$

For statin-refractory patients, options for adjunctive pharmacotherapy include: ezetimibe, a cholesterol absorption inhibitor, used in combination with statins; bile acid sequestrants or resins, e.g. colesevelam, which block reabsorption of lipids; peroxisome proliferator-activated receptor alpha agonists or fibrates, e.g. fenofibrate, which act mainly to increase HDL-C and lower triglycerides (TG); niacin/nicotinic acids, which mainly increase HDL-C and lower TG but also lower lipoprotein A, a highly atherogenic form of LDL-C; apolipoprotein B (apo B) inhibitors, e.g. mipomersen (adjunctive therapy in $\mathrm{HoFH}$ ); microsomal triglyceride transfer protein (MTP) inhibitor lomitapide (FH) and LDL apheresis for severe hypercholesterolaemia. ${ }^{10}$

\section{Guidelines and treatment algorithms}

The UK National Institute for Health and Care Excellence (NICE) lipid modification guidelines for the primary and secondary prevention of CVD recommend that benefits of lifestyle modification are discussed and management of modifiable CVD risk factors is optimised. ${ }^{11}$ Regarding treatment for the prevention of CVD, the NICE guidelines recommend atorvastatin $20 \mathrm{mg}$ for primary prevention in those with a $10 \%$ or greater 10 -year risk of developing CVD, and atorvastatin $80 \mathrm{mg}$ in people with CVD; in those unable to tolerate high-intensity statins, treatment should be with the maximum tolerated dose. People with primary hypercholesterolemia should be considered for ezetimibe monotherapy if statins are not tolerated or contraindicated, or ezetimibe in combination with a statin when cholesterol targets are not able to be met with statin therapy alone. ${ }^{11}$ Bile acid sequestrants and nicotinic acid should not be offered for primary or secondary prevention of CVD, alone or in combination with a statin.

Similarly, the European Society of Cardiology (ESC) guidelines recommend statins as first choice lipid-lowering therapy (LLT), and that these should be used at highest tolerated dose to reach target LDL-C levels before considering combination therapy. The ESC guidelines note that combinations of a statin with ezetimibe or, in contrast to the NICE guidelines, a bile acid sequestrant, may be used for greater reduction of LDL-C than can be achieved with either drug alone. ${ }^{1}$

ESC/European Atherosclerosis Society (EAS) guidelines on dyslipidemia treatment maintain that LDL-C remains the primary target of therapy in most strategies of dyslipidemia management. ${ }^{1}$ These 
guidelines recommend modulating the intensity of the preventive intervention according to total $\mathrm{CV}$ risk, suggesting target LDL-C levels of $<100 \mathrm{mg} / \mathrm{dL}$ in high risk patients, $<70 \mathrm{mg} / \mathrm{dL}$ in very high risk patients, with $<115 \mathrm{mg} / \mathrm{dL}$ suggested for patients at moderate risk. Choice of statin therapy should be that expected to produce the LDL-C reduction necessary for a given patient, with up-titration of the dose to reach the target. These guidelines recommend drug combinations with statins and bile acid sequestrants, ezetimibe or nicotinic acid if target levels are not reached. ${ }^{9}$

\section{Reasons for unmet need}

Despite the availability of numerous therapies, many patients with high cardiovascular risk do not achieve the LDL-C targets required to minimize their risk. ${ }^{1,7}$ This is due in part to a lack of efficacy or intolerance to statins and other treatments, as well as difficulties in reaching therapeutic targets. However, many patients fail to achieve LDL-C targets because of non-adherence to the drug regimen, reasons for which include the asymptomatic nature of hypercholesterolemia and low perceived risk among patients who have no personal history of CVD. Another major factor is undertreatment or inadequate treatment. ${ }^{12-14}$

\section{Novel therapies}

\section{Profile of an ideal lipid-modifying therapy for patients with high cardiovascular risk}

An ideal LMT for patients at high cardiovascular risk should be effective and well tolerated, while being convenient and easy to administer, and able to be used in all patient subsets, including those with renal or hepatic impairment and in elderly patients. An ideal agent would also be free from any major drug-drug interactions and would be able to be used in combination with statins in those failing to achieve LDL-C targets with statin therapy or as monotherapy in statin-intolerant patients. ${ }^{15}$ Among the most recent advances in clinical development are the proprotein convertase subtilisin/kexin 9 antibody (PCSK9) inhibitors. ${ }^{16}$

\section{Proprotein convertase subtilisin/kexin 9 antibody inhibitors}

\section{Alirocumab}

Alirocumab is a monoclonal antibody against PCSK9 currently approved in the US and EU. In the $\mathrm{EU}$, alirocumab is indicated in adults with primary hypercholesterolemia or mixed dyslipidemia, in combination with a statin or statin with other LLT in patients unable to reach LDL-C goals with the maximum tolerated dose of a statin. ${ }^{17}$ Alirocumab blocks the PCSK9 interactions with surface LDL receptor (LDLR) ${ }^{18}$ and has been shown to have a statin-enhancing effect. ${ }^{19}$

Three double-blind, placebo-controlled, phase II, randomized controlled trials of alirocumab of 8- or 12week duration in patients with hypercholesterolemia on background LMT confirmed the promising results in phase I studies. In a study of 183 patients with elevated LDL-C levels on stable atorvastatin, alirocumab was associated with reductions in LDL-C ranging from $40 \%$ to $72 \%$ for every 2 -week (Q2W) dosing and $43 \%$ to $48 \%$ with every 4 -week (Q4W) dosing. ${ }^{20}$ Alirocumab was generally well tolerated, but there was one rare event of leukocytoclastic vasculitis reported in this study and thought to be related to study drug administration by investigators. ${ }^{20}$

Alirocumab was also investigated at phase II in patients with $\mathrm{HeFH}$ receiving stable statin treatment with or without ezetimibe. ${ }^{21}$ In this 77-patient randomized, multicenter, placebo-controlled study, reductions in LDL-C levels after 12-week treatment were $29 \%, 32 \%$, and $43 \%$ in the alirocumab $150 \mathrm{mg}$, $200 \mathrm{mg}$, and $300 \mathrm{mg}$ Q4W groups, respectively, and $68 \%$ in the alirocumab $150 \mathrm{mg}$ Q2W group (compared with $11 \%$ in placebo recipients). ${ }^{21}$ In a subsequent phase II study, alirocumab was investigated in patients with elevated LDL-C levels after receiving atorvastatin $10 \mathrm{mg}$ for $\geq 7$ weeks. ${ }^{22}$ Significant reductions in LDL-C were seen with alirocumab 150 $\mathrm{mg}$ Q2W plus atorvastatin $10 \mathrm{mg} /$ day and atorvastatin $80 \mathrm{mg} /$ day, compared with atorvastatin $80 \mathrm{mg}$ /day plus placebo. ${ }^{22}$

The phase III ODYSSEY clinical trial program currently comprises 15 studies across a range of patient groups and clinical settings and involves more than 23,500 planned patients (Table 1). ${ }^{17,23-35}$ The primary results for the following ODYSSEY studies have been fully published: ODYSSEY COMBO $\mathrm{I}^{23}$ and II, ${ }^{24}$ ODYSSEY MONO, ${ }^{25}$ ODYSSEY FH I and II, ${ }^{26}$ ODYSSEY OPTIONS I ${ }^{27}$ and $\mathrm{II}^{28}$ ODYSSEY LONG TERM,${ }^{17}$ ODYSSEY HIGH FH,${ }^{29}$ ODYSSEY ALTERNATIVE, ${ }^{30}$ ODYSSEY CHOICE $\mathrm{I}^{31}$ and $\mathrm{II},{ }^{32}$ ODYSSEY ESCAPE, ${ }^{33}$ ODYSSEY JAPAN ${ }^{34}$ and ODYSSEY KT. ${ }^{35}$

The ODYSSEY FH I and II, ${ }^{26}$ ODYSSEY HIGH $\mathrm{FH}^{29}$ and ODYSSEY ESCAPE ${ }^{33}$ studies were multicenter, multinational, randomized, double-blind, placebo-controlled studies conducted in patients with HeFH. The ODYSSEY FH studies assessed efficacy and safety of alirocumab in patients with $\mathrm{HeFH}$ who, despite maximally-tolerated statin dose, with or without other LLT, continue to have suboptimal LDL$\mathrm{C}$ levels. In the ODYSSEY FH I and II studies, 735 such patients were randomized to SC alirocumab 75 mg Q2W or placebo with the alirocumab dose 
Table 1. Summary of alirocumab clinical trials: change in low-density lipoproteins-cholesterol from baseline to week 24.

\begin{tabular}{|c|c|c|c|c|c|c|c|}
\hline \multirow[t]{2}{*}{ Study } & \multirow[t]{2}{*}{ Patient population } & \multirow[t]{2}{*}{ Entry statin } & \multicolumn{5}{|c|}{ LDL-C change from baseline* } \\
\hline & & & Alirocumab & Placebo & $\begin{array}{l}\text { Ezetimibe } \\
10 \mathrm{mg} / \text { day }\end{array}$ & $\begin{array}{c}\text { Double statin } \\
\text { dose }\end{array}$ & $\begin{array}{l}\text { Switch to } \\
\text { rosuvastatin } \\
(40 \mathrm{mg} / \text { day })\end{array}$ \\
\hline ODYSSEY FH I ${ }^{26}$ & $\mathrm{HeFH}$ & NR & $\begin{array}{c}(\mathrm{n}=323) \\
-49 \%\end{array}$ & $\begin{array}{c}(\mathrm{n}=163) \\
9 \%\end{array}$ & - & - & - \\
\hline ODYSSEY FH II ${ }^{26}$ & $\mathrm{HeFH}$ & NR & $\begin{array}{c}(n=167) \\
-49 \%\end{array}$ & $\begin{array}{c}(\mathrm{n}=82) \\
3 \%\end{array}$ & - & - & - \\
\hline ODYSSEY COMBO I ${ }^{23}$ & $\begin{array}{l}\text { Hypercholesterolemia } \\
\text { in high CV risk } \\
\text { population }\end{array}$ & NR & $\begin{array}{c}(\mathrm{n}=205) \\
-48 \%\end{array}$ & $\begin{array}{c}(\mathrm{n}=106) \\
-2 \%\end{array}$ & - & - & - \\
\hline ODYSSEY COMBO II ${ }^{24}$ & $\begin{array}{l}\text { Hypercholesterolemia } \\
\text { in high CV risk } \\
\text { population }\end{array}$ & $\begin{array}{l}\text { Atorvastatin, } \\
\text { rosuvastatin, } \\
\text { simvastatin }\end{array}$ & $\begin{array}{c}(\mathrm{n}=467) \\
-51 \%\end{array}$ & $\begin{array}{l}(\mathrm{n}=240) \\
-21 \%\end{array}$ & - & - & - \\
\hline ODYSSEY MONO ${ }^{25}$ & $\begin{array}{l}\text { Hypercholesterolemia } \\
\text { not on other LLT }\end{array}$ & NR & $\begin{array}{l}(n=52) \\
-47 \%\end{array}$ & - & $\begin{array}{l}(\mathrm{n}=51) \\
-16 \%\end{array}$ & - & - \\
\hline $\begin{array}{l}\text { ODYSSEY } \\
\text { OPTIONS I }{ }^{27}\end{array}$ & $\begin{array}{l}\mathrm{HeFH} \text { or uncontrolled } \\
\text { primary } \\
\text { hypercholesterolemia } \\
\text { at high CV risk }\end{array}$ & $\begin{array}{l}\text { Atorvastatin } \\
20 \mathrm{mg} \\
\text { Atorvastatin } \\
40 \mathrm{mg}\end{array}$ & $\begin{array}{l}(\mathrm{n}=55) \\
-44 \% \\
(\mathrm{n}=46) \\
-54 \%\end{array}$ & - & $\begin{array}{l}(\mathrm{n}=53) \\
-21 \% \\
(\mathrm{n}=46) \\
-23 \%\end{array}$ & $\begin{array}{c}(\mathrm{n}=53) \\
-5 \% \\
(\mathrm{n}=47) \\
-5 \%\end{array}$ & $\begin{array}{c}- \\
(\mathrm{n}=45) \\
-21 \%\end{array}$ \\
\hline $\begin{array}{l}\text { ODYSSEY } \\
\text { OPTIONS II }{ }^{28}\end{array}$ & $\begin{array}{l}\mathrm{HeFH} \text { or uncontrolled } \\
\text { primary } \\
\text { hypercholesterolemia } \\
\text { at high CV risk }\end{array}$ & $\begin{array}{l}\text { Rosuvastatin } \\
10 \mathrm{mg} \\
\text { Rosuvastatin } \\
20 \mathrm{mg}\end{array}$ & $\begin{array}{l}(\mathrm{n}=48) \\
-51 \% \\
(\mathrm{n}=53) \\
-36 \%\end{array}$ & - & $\begin{array}{l}(\mathrm{n}=47) \\
-14 \% \\
(\mathrm{n}=50) \\
-11 \%\end{array}$ & $\begin{array}{l}(\mathrm{n}=48) \\
-16 \% \\
(\mathrm{n}=52) \\
-16 \%\end{array}$ & - \\
\hline $\begin{array}{l}\text { ODYSSEY } \\
\text { LONG TERM }^{17}\end{array}$ & $\begin{array}{l}\mathrm{HeFH} \text { and } \\
\text { hypercholesterolemia } \\
\text { in high CV risk } \\
\text { population }\end{array}$ & NR & $\begin{array}{c}(\mathrm{n}=1530) \\
-61 \%\end{array}$ & $\begin{array}{c}(\mathrm{n}=780) \\
1 \%\end{array}$ & - & - & - \\
\hline ODYSSEY HIGH FH ${ }^{29}$ & $\mathrm{HeFH}$ & NR & $\begin{array}{l}(\mathrm{n}=71) \\
-46 \%\end{array}$ & $\begin{array}{l}(\mathrm{n}=35) \\
-7 \%\end{array}$ & - & - & - \\
\hline $\begin{array}{l}\text { ODYSSEY } \\
\text { ALTERNATIVE }\end{array}$ & $\begin{array}{l}\text { Statin-intolerant } \\
\text { patients with primary } \\
\text { hypercholesterolemia } \\
\text { (familial and non-familial) }\end{array}$ & $\begin{array}{l}\mathrm{NR} \\
\mathrm{NR}\end{array}$ & $\begin{array}{c}(\mathrm{n}=126) \\
-45 \% \\
(\mathrm{n}=183) \\
-52.7 \%\end{array}$ & $\begin{array}{l}(\mathrm{n}=122) \\
-15 \% \\
(\mathrm{n}=73) \\
-0.3 \%\end{array}$ & - & - & - \\
\hline ODYSSEY CHOICE I ${ }^{31}$ & $\begin{array}{l}\text { Hypercholesterolemia } \\
\text { in moderate-to-very } \\
\text {-high CV risk } \\
\text { population }\end{array}$ & $\begin{array}{l}\text { Rosuvastatin } \\
(20-40 \mathrm{mg}), \\
\text { atorvastatin } \\
(40-80 \mathrm{mg}) \text { or } \\
\text { simvastatin } \\
(80 \mathrm{mg})\end{array}$ & $\begin{array}{l}(\mathrm{n}=390) \\
-58.8 \%\end{array}$ & $\begin{array}{c}(\mathrm{n}=157) \\
-0.1 \%\end{array}$ & - & - & - \\
\hline ODYSSEY CHOICE II ${ }^{32}$ & $\begin{array}{l}\text { Hypercholesterolemia, } \\
\text { not receiving a statin }\end{array}$ & NR & $\begin{array}{l}(\mathrm{n}=116) \\
-53.5 \%\end{array}$ & $\begin{array}{c}(\mathrm{n}=58) \\
4.7 \%\end{array}$ & - & - & - \\
\hline ODYSSEY ESCAPE ${ }^{33}$ & $\begin{array}{l}\text { HeFH undergoing } \\
\text { regular } \\
\text { (weekly or Q2W) } \\
\text { lipoprotein apheresis }\end{array}$ & NR & $\begin{array}{c}(\mathrm{n}=41) \\
-53.7 \%\end{array}$ & $\begin{array}{c}(\mathrm{n}=21) \\
1.6 \%\end{array}$ & - & - & - \\
\hline ODYSSEY JAPAN ${ }^{34}$ & $\begin{array}{l}\text { HeFH, non-FH with } \\
\text { high CV risk or } \\
\text { category III } \\
\text { classification, } \\
\text { in Japan }\end{array}$ & NR & $\begin{array}{l}(n=144) \\
-62.5 \%\end{array}$ & $\begin{array}{c}(\mathrm{n}=72) \\
1.6 \%\end{array}$ & - & - & - \\
\hline ODYSSEY KT ${ }^{35}$ & $\begin{array}{l}\text { Hypercholesterolemia, } \\
\text { with high CV risk, } \\
\text { taking maximum } \\
\text { tolerated statin dose, } \\
\text { from South Korea } \\
\text { or Taiwan }\end{array}$ & $\begin{array}{l}\text { Atorvastatin } \\
\text { rosuvastatin or } \\
\text { simvastatin }\end{array}$ & $\begin{array}{l}(\mathrm{n}=97) \\
-57.1 \%\end{array}$ & $\begin{array}{c}(\mathrm{n}=102) \\
6.3 \%\end{array}$ & - & - & - \\
\hline
\end{tabular}

*Least squares mean change from baseline. LDL-C, low-density lipoproteins-cholesterol; HeFH, heterozygous familial hypercholesterolemia; CV, cardiovascular; LLT, lipid-lowering therapy; Q2W, every 2 weeks; Q4W, every 4 weeks. 
increased to $150 \mathrm{mg}$ Q2W if LDL-C remained $>70$ $\mathrm{mg} / \mathrm{dL}$ after 8 weeks. Alirocumab significantly reduced LDL-C from baseline to week 24 compared with placebo and safety and tolerability were generally comparable in the two groups. ${ }^{26}$

ODYSSEY HIGH-FH randomized a total of 107 $\mathrm{HeFH}$ patients with LDL-C levels $\geq 160 \mathrm{mg} / \mathrm{dL}$ despite maximally tolerated treatment with statins and other LLT to alirocumab $150 \mathrm{mg}$ Q2W or placebo. ${ }^{29}$ Significant reductions in LDL-C from baseline to week 24 were observed with alirocumab, compared with placebo. Alirocumab was generally well tolerated and total adverse events were comparable with the placebo group.

ODYSSEY ESCAPE evaluated the effect of alirocumab on the frequency of apheresis treatments in patients with $\mathrm{HeFH}^{33}$ In this double-blind, randomized trial, patients receiving alirocumab 150 $\mathrm{mg}$ had a significant change in pre-apheresis LDL-C, compared with those receiving placebo.

The ODYSSEY ALTERNATIVE study investigated the role of alirocumab, compared with ezetimibe in patients with primary hypercholesterolemia and moderate, high, or very high $\mathrm{CV}$ risk, intolerant to statins. ${ }^{30} \mathrm{After}$ a 4 -week placebo run-in phase, 314 patients were randomized to SC alirocumab 75 or $150 \mathrm{mg}$ Q2W, ezetimibe $10 \mathrm{mg} /$ day, or atorvastatin $20 \mathrm{mg} /$ day for 24 weeks. Alirocumab resulted in a significant reduction from baseline than ezetimibe; adverse events were similar between groups.

ODYSSEY COMBO I and II were designed to evaluate the long-term efficacy and safety of alirocumab as add-on therapy to stable, maximally tolerated, daily statin therapy in patients with hypercholesterolemia at high cardiovascular risk. ${ }^{23,24}$ In COMBO I, 316 patients were randomized to alirocumab $75 \mathrm{mg}$ Q2W (with the potential to increase to $150 \mathrm{mg}$ Q2W) or placebo. ${ }^{23}$ Alirocumab was associated with significant reductions in LDL-C; treatment-emergent adverse events were generally comparable between the two groups. In the 104-week COMBO II study, patients were randomized to alirocumab $75 \mathrm{mg}$ Q2W or ezetimibe $10 \mathrm{mg}$ /day on a background of stable statin therapy. ${ }^{24}$ At 24 weeks, there was a LS mean difference in reduction in LDL$\mathrm{C}$ from baseline between alirocumab and ezetimibe of $-30 \%$. In COMBO II, the LDL-C lowering ability of alirocumab was maintained over 2 years of treatment, with a significant reduction in LDL-C at 2 years with alirocumab, compared with ezetimibe ${ }^{36}$ Alirocumab was generally well tolerated, with no evidence of an excess of treatment-emergent adverse events. ${ }^{24,36}$

In ODYSSEY MONO, alirocumab monotherapy was investigated in 103 patients with LDL-C 100-190 $\mathrm{mg} / \mathrm{dL}$ and an estimated 10-year fatal CVD risk SCORE $\geq 1 \%$ and $<5 \%$. Patients were randomly assigned to alirocumab $75 \mathrm{mg}$ Q2W or ezetimibe 10 $\mathrm{mg} /$ day. ${ }^{25}$ After 24 weeks, the alirocumab group showed a significant reduction in LDL-C; adverse events were similar between the two groups.

ODYSSEY OPTIONS I and II, investigated alirocumab as add-on to statin therapy (atorvastatin 20 or $40 \mathrm{mg} /$ day in OPTIONS I; ${ }^{27}$ rosuvastatin 10 or 20 $\mathrm{mg} /$ day in OPTIONS $\mathrm{II}^{28}$ ) compared with intensification of statin therapy, switching statin therapy or the addition of ezetimibe in patients at high cardiovascular risk and elevated LDL-C levels. ${ }^{27,28} \mathrm{~A}$ total of 660 patients were randomized and, at week 24 , alirocumab significantly reduced LDL-C levels in patients receiving atorvastatin 20 or $40 \mathrm{mg}$ at baseline or rosuvastatin $10 \mathrm{mg}$ at baseline.

ODYSSEY CHOICE I and II evaluated the effect of alirocumab in patients with hypercholesterolemia receiving LLTs with either a maximum statin dose or no statin (CHOICE I) ${ }^{31}$ or with inadequately controlled hypercholesterolemia, not on statins, receiving treatment with fenofibrate, ezetimibe, or diet (CHOICE II). ${ }^{32}$ In ODYSSEY CHOICE I, LDL-C was significantly reduced from baseline to week 24 in patients receiving alirocumab $300 \mathrm{mg}$ every 4 weeks (Q4W) compared with placebo. ${ }^{31}$ In CHOICE II patients who received alirocumab (150 mg Q4W or 75 $\mathrm{mg}$ Q2W) had a $-51.7 \%$ and $-53.5 \%$ change in mean LDL-C from baseline to week 24, compared with an increase of $4.7 \%$ in the placebo group. ${ }^{32}$ Treatmentemergent adverse events were similar between treatment and placebo groups in both studies and ranged from $61.1-75.0 \%$ in the placebo group of both studies, $71.5-78.1 \%$ in alirocumab $300 \mathrm{mg}$ Q4W (CHOICE I), ${ }^{31} 77.6 \%$ in alirocumab $150 \mathrm{mg} \mathrm{Q} 4 \mathrm{~W}$ and $73.0 \%$ in alirocumab $75 \mathrm{mg}$ Q2W (CHOICE II). ${ }^{32}$

ODYSSEY LONG TERM was a 78-week trial comparing alirocumab (150 mg Q2W) with placebo in 2341 patients at high cardiovascular risk receiving treatment with maximally tolerated statin doses with or without other LLT. ${ }^{17}$ All patients had elevated LDL$\mathrm{C}(\geq 70 \mathrm{mg} / \mathrm{dL})$ despite LLT for $\geq 4$ weeks prior to screening. Patients were randomized to alirocumab $150 \mathrm{mg}$ or placebo Q2W for 78 weeks. At week 24, the mean change from baseline in LDL-C between alirocumab and placebo was $-62 \%$, and the treatment effect remained consistent up to 78 weeks; the percentage of patients with any adverse event was similar in the two study groups. In a post hoc analysis, the rate of major adverse cardiovascular events was lower with alirocumab than with placebo $(1.7 \% v s$ 3.3\%; hazard ratio: $0.52 ; 95 \%$ confidence interval: $0.31-0.90 ; \mathrm{P}=0.02){ }^{17}$

The role of alirocumab in Asian patients was investigated in ODYSSEY JAPAN and ODYSSEY KT. ODYSSEY JAPAN was conducted in 216 Japanese patients with $\mathrm{HeFH}$ or patients with 
hypercholesterolemia at high cardiovascular risk and found that alirocumab significantly reduced LDL-C, compared with placebo. The reduction was sustained over 52 weeks. ${ }^{34}$ ODYSSEY KT, which investigated the efficacy and safety of alirocumab in patients from South Korea and Taiwan, found that LDL-C was significantly reduced after 24 weeks in patients receiving alirocumab, compared with placebo. ${ }^{35} \mathrm{In}$ both studies, treatment-emergent adverse events were comparable between both groups. . $^{34,35}$

The role of alirocumab in reducing cardiovascular morbidity and mortality in patients with recent acute coronary syndrome and elevated levels of LDL-C despite therapy with intensive (or maximally tolerated doses) of atorvastatin or rosuvastatin was further investigated in the phase III placebo-controlled ODYSSEY OUTCOMES trial. ${ }^{37}$ Patients were randomized to receive subcutaneous alirocumab 75$150 \mathrm{mg}$ Q2W or placebo, with cardiovascular events as the primary efficacy endpoint. Due to the high pricing of alirocumab, patients with $\mathrm{HeFH}$ and those with atherosclerotic CVD who have significantly elevated LDL-C on maximally tolerated statin plus ezetimibe were prioritized for treatment. Based on subgroup analysis of ODYSSEY OUTCOMES trial, the cost-benefit ratio is likely to favor patients with an event associated with acute coronary syndrome within the preceding 12 months. ${ }^{38,39}$

\section{Evolocumab}

Evolocumab is a PCSK9 inhibitor, which is approved in Europe for the treatment of adults with primary hypercholesterolemia $(\mathrm{HeFH}$ and nonfamilial), mixed dyslipidemias and $\mathrm{HoFH}$ in combination with other lipid-lowering therapies and in the US for patients with $\mathrm{HeFH}, \mathrm{HoFH}$ or clinical atherosclerotic CVD also receiving the maximallytolerated statin therapy. Evolocumab has been evaluated in several phase III studies in various patient subsets (Table 2). ${ }^{40-49}$ In the phase III DESCARTES randomized controlled 52-week trial, evolocumab added to diet, or to atorvastatin with or without ezetimibe significantly reduced LDL-C levels in patients with a range of cardiovascular risk. ${ }^{40}$ Similarly, in the MENDEL-2 trial conducted in a large population of patients with primary hypercholesterolemia not confounded by statin use or a history of statin intolerance, evolocumab reduced LDL-C from baseline. ${ }^{41}$ The 12-week GAUSS-2 phase III study compared evolocumab 140 mg Q2W or $420 \mathrm{mg}$ Q4W with daily oral ezetimibe $10 \mathrm{mg}$ in 307 statin-intolerant hypercholesterolemic patients and also demonstrated significant reductions in LDL-C from baseline for evolocumab compared with ezetimibe ${ }^{42}$ In the TESLA phase III study, evolocumab was investigated in patients with $\mathrm{HoFH}$

Table 2. Summary of evolocumab clinical trials: change in low-density lipoproteins-cholesterol from baseline to week 12.

\begin{tabular}{|c|c|c|c|c|c|c|c|}
\hline \multirow[t]{3}{*}{ Study } & \multirow[t]{3}{*}{ Patient population } & \multicolumn{6}{|c|}{ LDL-C change from baseline* } \\
\hline & & \multicolumn{2}{|c|}{ Evolocumab } & \multicolumn{2}{|c|}{ Placebo } & \multicolumn{2}{|c|}{ Ezetimibe } \\
\hline & & 140 Q2W & 420 Q4W & Q2W & Q4W & Q2W & Q4W \\
\hline MENDEL-2 ${ }^{41}$ & Patients not receiving drug therapy & $\begin{array}{l}(\mathrm{n}=153) \\
-57 \%\end{array}$ & $\begin{array}{l}(\mathrm{n}=153) \\
-56 \%\end{array}$ & $\begin{array}{l}(\mathrm{n}=76) \\
-0.1 \%\end{array}$ & $\begin{array}{l}(\mathrm{n}=78) \\
-3.2 \%\end{array}$ & $\begin{array}{l}(\mathrm{n}=77) \\
-18 \%\end{array}$ & $\begin{array}{l}(\mathrm{n}=77) \\
-19 \%\end{array}$ \\
\hline GAUSS-2 ${ }^{42}$ & Hypercholesterolemia intolerant to statins & $\begin{array}{c}(\mathrm{n}=103) \\
-56 \%\end{array}$ & $\begin{array}{c}(\mathrm{n}=102) \\
-55 \%\end{array}$ & - & - & $\begin{array}{l}(\mathrm{n}=51) \\
-19 \%\end{array}$ & $\begin{array}{l}(\mathrm{n}=51) \\
-17 \%\end{array}$ \\
\hline \multirow[t]{2}{*}{ TESLA Part B ${ }^{43}$} & HoFH not on apheresis & - & $(\mathrm{n}=33)$ & - & $(\mathrm{n}=16)$ & - & - \\
\hline & & & $-23 \%$ & & $8 \%$ & & \\
\hline RUTHERFORD-2 ${ }^{44}$ & $\mathrm{HeFH}$ & $\begin{array}{c}(\mathrm{n}=110) \\
-61 \%\end{array}$ & $\begin{array}{c}(\mathrm{n}=110) \\
-56 \%\end{array}$ & $\begin{array}{l}(\mathrm{n}=54) \\
-2 \%\end{array}$ & $\begin{array}{c}(\mathrm{n}=55) \\
5.5 \%\end{array}$ & - & - \\
\hline LAPLACE-2 $2^{45}$ & Hypercholesterolemia on background statins & $\begin{array}{c}-59 \% \text { to } \\
-66 \%\end{array}$ & $\begin{array}{c}-62 \% \text { to } \\
-65 \%\end{array}$ & $\begin{array}{c}3 \% \text { to } \\
13 \%\end{array}$ & $\begin{array}{c}0 \% \text { to } \\
10 \%\end{array}$ & $\begin{array}{l}-17 \% \text { to } \\
-24 \%\end{array}$ & $\begin{array}{c}-19 \% \text { to } \\
-21 \%\end{array}$ \\
\hline $\begin{array}{l}\text { DESCARTES } \\
\text { (week 52) }\end{array}$ & Hyperlipidemia and mixed dyslipidemia & - & $\begin{array}{c}(\mathrm{n}=599) \\
-57 \%\end{array}$ & - & $\begin{array}{c}(\mathrm{n}=302) \\
7 \%\end{array}$ & - & - \\
\hline GLAGOV $^{47}$ & $\begin{array}{l}\text { Patients with angiographic coronary disease, } \\
\text { currently on statins }\end{array}$ & - & $\begin{array}{c}(\mathrm{n}=484) \\
-56.3 \mathrm{mg} / \mathrm{dL}\end{array}$ & - & $\begin{array}{c}(\mathrm{n}=484) \\
0.2 \mathrm{mg} / \mathrm{dL}\end{array}$ & - & - \\
\hline \multirow[t]{2}{*}{ FOURIER $^{48}$} & \multirow{2}{*}{$\begin{array}{l}\text { Patients with atherosclerotic CVD with LDL-C } \\
\geq 70 \mathrm{mg} / \mathrm{dL} \text {, currently on statins }\end{array}$} & \multicolumn{2}{|c|}{$(\mathrm{n}=13,784)$} & \multicolumn{2}{|c|}{$(\mathrm{n}=13,780)$} & \multirow[t]{2}{*}{ - } & \multirow[t]{2}{*}{-} \\
\hline & & & Between-groul & ifference & $61 \%$ & & \\
\hline TAUSSIG $^{49}$ & HoFH, on LLT & - & $\begin{array}{l}(\mathrm{n}=106) \\
-23.3 \%\end{array}$ & - & - & - & - \\
\hline
\end{tabular}

*Least squares mean change from baseline; ${ }^{\circ}$ mean of week 10 and week 12 . LDL-C, low-density lipoproteins-cholesterol; Q2W, every 2 weeks; Q4W, every 4 weeks HoFH, homozygous familial hypercholesterolemia; HeFH, heterozygous familial hypercholesterolemia; CVD, cardiovascular disease; LLT, lipid-lowering therapy. 
receiving LLT. ${ }^{43}$ Patients were randomized to evolocumab $420 \mathrm{mg}$ or placebo Q4W, with evolocumab significantly reducing LDL-C at 12 weeks. Evolocumab has also been investigated in $\mathrm{HeFH}$ patients with elevated LDL-C despite intense LLT, in RUTHERFORD-2, compared with placebo, evolocumab led to significant reductions in mean LDL-C at week 12 and was well tolerated, with rates of adverse events similar to placebo. ${ }^{44}$

The LAPLACE-2 study evaluated evolocumab versus placebo or ezetimibe in patients randomized to different background statin therapies ${ }^{45}$ Reductions in LDL-C were similar across statin groups for evolocumab administered every 2 weeks and monthly.

Patients from 12 phase II or III parent trials of evolocumab were enrolled into one of two long-term extension studies (OSLER and OSLER-2) and randomized to standard care plus evolocumab 420 mg Q4W or standard care alone in OLSER-1, with OLSER-2 patients given a choice of $140 \mathrm{mg}$ Q2Wor $420 \mathrm{mg}$ Q4W. Evolocumab had a 12-week reduction in LDL-C of $61 \%$ compared with standard care, with this reduction sustained through to 48 weeks $(58 \%))^{46}$

In terms of LDL-C level reduction with a PCSK9 inhibitor leading to a reduction in cardiovascular events, in the OSLER studies, patients in the evolocumab group had a significantly lower rate of all cardiovascular events than patients receiving standard therapy (Kaplan-Meier estimates at 1 year, $0.95 \%$ and $2.18 \%$, respectively; hazard ratio, 0.47$){ }^{46}$ The GLAGOV study, which enrolled 968 patients presenting for coronary angiography, found that patients receiving evolocumab achieved a lower mean time-weighted LDL-C, compared with patient receiving placebo. The primary efficacy endpoint of nominal change in percent atheroma volume from baseline to week 78 increased by $0.05 \%$ with placebo and decreased by $0.95 \%$ with evolocumab $(\mathrm{P}<0.001) .{ }^{47}$ Furthermore, patients receiving evolocumab in the FOURIER study, a randomized placebo-controlled trial involving 27,500 high-risk patients with CVD receiving background statin therapy, had significantly reduced risk of the major cardiovascular events, compared with patients receiving placebo. ${ }^{48}$

In an interim analysis of the phase III, nonrandomized, open-label TAUSSIG trial, which is investigating the long-term efficacy and safety of evolocumab, patients with HoFH who received stable LLT for at least 4 weeks, with or without apheresis, had a reduction in LDL-C after 12 weeks of evolocumab. ${ }^{49}$ TAUSSIG is still ongoing and final results from this trial are needed to confirm this finding.

\section{Marketed agents for homozygous familial hypercholesterolemia only}

\section{Lomitapide}

Lomitapide, an inhibitor of MTP, ${ }^{50}$ was approved in Europe in 2012 as adjunctive therapy to a low-fat diet and other LMTs with or without LDL apheresis in adult patients with HoFH.

In a multinational, phase III single-arm open-label study of lomitapide $5 \mathrm{mg} /$ day to $60 \mathrm{mg}$ /day for $\mathrm{HoFH}$ in 29 patients with elevated LDL-C despite LLT, including LDL apheresis, LDL cholesterol was reduced by $50 \%$ from baseline to week $26 .{ }^{51}$ Of note, four patients had amino transaminase levels of more than five times the upper limit of normal, which resolved after dose reduction or temporary interruption of lomitapide. The extension of the phase III trial showed consistent findings with the original trial and indicated that lomitapide treatment in adjunct to other LLTs was highly effective in lowering LDL$\mathrm{C}$ levels with acceptable tolerability and no new safety concerns. ${ }^{52}$

\section{Mipomersen}

Mipomersen is an antisense oligonucleotide that inhibits the synthesis of apo B, an essential component of LDL-C. ${ }^{33}$ Mipomersen was approved in 2013 by the US FDA as an adjunct to lipid-lowering medications and diet to reduce LDL-C, apo B, total cholesterol, and non-HDL-C in patients with $\mathrm{HoFH}$; it is not approved in Europe. Clinical trial data revealed consistent decreases in LDL-C with mipomersen in a range of patient populations (Table 3). ${ }^{54-60}$

There is evidence of an increased risk of transaminase elevations in patients receiving mipomersen. In an open-label, long-term efficacy and safety study of mipomersen, reduction in all atherosclerotic lipoproteins and an acceptable safety profile was sustained for up to 104 weeks in high-risk patient populations..$^{54}$

The US FDA labelling information for both lomitapide and mipomersen carries a Black Box warning about the serious risk of liver toxicity.

\section{Conclusions}

Current management of hypercholesterolemia is challenging in patients with high cardiovascular risk and many patients do not achieve their therapeutic target despite maximal treatment with statins with or without other LMTs. Inadequate LDL-C control is associated with increased risk of cardiovascularrelated events/mortality. Available evidence suggests that additional agents may have a role in the future of hypercholesterolemia management (Table 4). Results from the ODYSSEY OUTCOMES and FOURIER 
Table 3. Summary of mipomersen clinical data: change in low-density lipoproteins-cholesterol levels from baseline.

\begin{tabular}{|c|c|c|c|c|}
\hline \multirow[t]{2}{*}{ Study } & \multirow[t]{2}{*}{ Patient population } & \multirow{2}{*}{$\begin{array}{l}\text { Mipomersen dose } \\
\text { (mg/week) }\end{array}$} & \multicolumn{2}{|c|}{ LDL-C change from baseline* } \\
\hline & & & Mipomersen & Placebo \\
\hline Akdim et al., $2010^{55}$ & Hypercholesterolemia on stable statins & 30 to 400 & $\begin{array}{c}(\mathrm{n}=49) \\
-21 \% \text { to }-52 \%^{\text {o,\# }} \text { (week 5) }\end{array}$ & $\begin{array}{c}(\mathrm{n}=13) \\
-3 \% \text { (week 5) }\end{array}$ \\
\hline Akdim et al., $2010^{56}$ & $\mathrm{HeFH}$ on stable LLT & 50 to 300 & $\begin{array}{c}(\mathrm{n}=36) \\
-11 \% \text { to }-34 \%^{\circ}(\text { week } 6)\end{array}$ & $\begin{array}{c}(\mathrm{n}=8) \\
0 \% \text { (week 6) }\end{array}$ \\
\hline Raal et al., $2010^{57}$ & HoFH, maximally tolerated LLT & 200 & $\begin{array}{c}(\mathrm{n}=34) \\
-25 \% \text { (week 28) }\end{array}$ & $\begin{array}{c}(\mathrm{n}=17) \\
-3 \% \text { (week } 28)\end{array}$ \\
\hline McGowan et al., $2012^{58}$ & Severe hypercholesterolemia on maximal statins & 200 & $\begin{array}{c}(\mathrm{n}=39) \\
-36 \% \text { (week 28) }\end{array}$ & $\begin{array}{c}(\mathrm{n}=18) \\
+13 \% \text { (week 28) }\end{array}$ \\
\hline Thomas et al., $2013^{59}$ & Severe hypercholesterolemia at high CV risk & 200 & $\begin{array}{c}(\mathrm{n}=101) \\
-37 \% \text { (week 28) }\end{array}$ & $\begin{array}{c}(\mathrm{n}=50) \\
-5 \% \text { (week 28) }\end{array}$ \\
\hline Visser et al., $2012^{60}$ & High-risk CV statin intolerant & 200 & $\begin{array}{c}(\mathrm{n}=21) \\
-47 \% \text { (Week 28) }\end{array}$ & $\begin{array}{c}(\mathrm{n}=12) \\
-2 \%(\text { week } 28)\end{array}$ \\
\hline
\end{tabular}

*Least squares mean change from baseline; ${ }^{\circ}$ for doses of $100 \mathrm{mg} /$ week or higher; ${ }^{*}$ for patients who received mipomersen over a 5-week period. LDL-C, low-density lipoproteinscholesterol; HeFH, heterozygous familial hypercholesterolemia; LLT, lipid-lowering therapy; CV, cardiovascular.

Table 4. Approved and proposed clinical role of novel lipid-modifying therapies in the high cardiovascular risk population based on current evidence.

\begin{tabular}{ll}
\hline Therapy & Approved role \\
\hline Alirocumab & $\begin{array}{l}\text { Indicated adjunct to diet and maximally tolerated statin therapy for treatment of adults with HeFH or clinical atherosclerotic } \\
\text { CVD who require additional lowering of LDL-C }\end{array}$ \\
Evolocumab & $\begin{array}{l}\text { Indicated adjunct to diet and maximally tolerated statin therapy for treatment of adults with HeFH or clinical atherosclerotic } \\
\text { CVD who require additional lowering of LDL-C; indicated adjunct to other LDL lowering therapies (statins, ezetimibe, LDL } \\
\text { apheresis) in patients with HoFH who require additional lowering of LDL-C }\end{array}$ \\
\hline & Proposed role \\
\hline $\begin{array}{l}\text { Lomitapide } \\
\text { Mipomersen }\end{array}$ & $\begin{array}{l}\text { Adjunctive therapy in HoFH only } \\
\text { HoFH only }\end{array}$ \\
\hline
\end{tabular}

$\mathrm{HeFH}$, heterozygous familial hypercholesterolemia; CVD, cardiovascular disease; LDL-C, low-density lipoproteins-cholesterol; HoFH, homozygous familial hypercholesterolemia.

studies provided evidence for the efficacy of alirocumab and evolocumab in improving CVD outcomes in patients with elevated LDL-C. Lomitapide and mipomersen are approved for the treatment of $\mathrm{HoFH}$, but their use in other hypercholesterolemias and dyslipidemias is not indicated. Novel agents, such as the PCSK9 inhibitors, will better meet the needs of this diverse population to allow more patients to achieve lipid goals and permit further reductions in cardiovascular risk.

\section{References}

1. Piepoli MF, Hoes AW, Agewall S, et al. 2016 European Guidelines on cardiovascular disease prevention in clinical practice: The Sixth Joint Task Force of the European Society of Cardiology and Other Societies on Cardiovascular Disease Prevention in Clinical Practice (constituted by representatives of 10 societies and by invited experts) Developed with the special contribution of the European Association for Cardiovascular
Prevention \& Rehabilitation (EACPR). Atherosclerosis 2016;252:207-74.

2. Khera AV, Won H-H, Peloso GM, et al. Diagnostic yield and clinical utility of sequencing familial hypercholesterolemia genes in patients with severe hypercholesterolemia. J Am Coll Cardiol 2016;67: 2578-89.

3. Kachkovskii M. Secondary hypercholesterinemia as a new global problem. Atherosclerosis 2017;263:e179.

4. Youngblom E, Pariani M, Knowles JW. Familial hypercholesterolemia. In: GeneReviews. 2016. Available from: http:/www.ncbi.nlm.nih.gov/books/NBK174884/

5. Rosenson RS, Baker S, Banach M et al. Optimizing cholesterol treatment in patients with muscle complaints. J Am Coll Cardiol 2017;70:1290-301.

6. Collins DR, Tompson AC, Onakpoya IJ, et al. Global cardiovascular risk assessment in the primary prevention of cardiovascular disease in adults: systematic review of systematic reviews. BMJ Open 2017;7:e013650.

7. Goff DC Jr., Lloyd-Jones DM, Bennett G, et al. 2013 ACC/AHA guideline on the assessment of cardiovascular risk: a report of the American College of Cardiology/American Heart Association Task Force on Practice Guidelines. J Am Coll Cardiol 2014;63:2935-59. 
8. Conroy R, Pyörälä K, Fitzgerald A, et al. Estimation of ten-year risk of fatal cardiovascular disease in Europe: the SCORE project. Eur Heart J 2003;24:987-1003.

9. Catapano AL, Graham I, De Backer G, et al. 2016 ESC/EAS guidelines for the management of dyslipidaemias. Eur Heart J 2016;37:2999-3058.

10. Chang Y, Robidoux J. Dyslipidemia management update. Curr Opin Pharmacol 2017;33:47-55.

11. National Institute for Health and Clinical Excellence (NICE). Lipid modification: Cardiovascular risk assessment and the modification of blood lipids for the primary and secondary prevention of cardiovascular disease: NICE guidelines [CG181]. http://www.nice.org. uk/guidance/CG181. Accessed: 17 April 2018.

12. Executive summary of the third report of the National Cholesterol Education Program (NCEP) expert panel on detection, evaluation, and treatment of high blood cholesterol in adults (Adult Treatment Panel III). JAMA 2001;285:2486-97.

13. Stone NJ, Robinson JG, Lichtenstein AH, et al. 2013 ACC/AHA guideline on the treatment of blood cholesterol to reduce atherosclerotic cardiovascular risk in adults: a report of the American College of Cardiology/American Heart Association Task Force on Practice Guidelines. J Am Coll Cardiol 2014;63:2889-934.

14. Lloyd-Jones DM, Morris PB, Ballantyne CM, et al. 2016 ACC expert consensus decision pathway on the role of non-statin therapies for LDL-cholesterol lowering in the management of atherosclerotic cardiovascular disease risk: a report of the American College of Cardiology Task Force on Clinical Expert Consensus Documents. J Am Coll Cardiol 2016;68:92-125.

15. Arca M, Ansell D, Averna M, et al. Statin utilization and lipid goal attainment in high or very-high cardiovascular risk patients: insights from Italian general practice. Atherosclerosis 2018;271:120-7.

16. Denegri A, Petrova-Slater I, Pasotti E, et al. PCSK9 inhibitors: an overview on a new promising lipidlowering therapy. J Cardiovasc Med (Hagerstown) 2016;17:237-44.

17. Robinson JG, Farnier M, Krempf M, et al. Efficacy and safety of alirocumab in reducing lipids and cardiovascular events. N Engl J Med 2015;372:1489-99.

18. Roth EM, Diller P. Alirocumab for hyperlipidemia: physiology of PCSK9 inhibition, pharmacodynamics and phase I and II clinical trial results of a PCSK9 monoclonal antibody. Future Cardiol 2014;10:183-99.

19. Kuhnast S, van der Hoorn JW, Pieterman EJ, et al. Alirocumab inhibits atherosclerosis, improves the plaque morphology, and enhances the effects of a statin. J Lipid Res 2014;55:2103-12.

20. McKenney JM, Koren MJ, Kereiakes DJ, et al. Safety and efficacy of a monoclonal antibody to proprotein convertase subtilisin/kexin type 9 serine protease, SAR236553/REGN727, in patients with primary hypercholesterolemia receiving ongoing stable atorvastatin therapy. J Am Coll Cardiol 2012;59:2344-53.

21. Stein EA, Gipe D, Bergeron J, et al. Effect of a monoclonal antibody to PCSK9, REGN727/SAR236553, to reduce low-density lipoprotein cholesterol in patients with heterozygous familial hypercholesterolaemia on stable statin dose with or without ezetimibe therapy: a phase 2 randomised controlled trial. Lancet 2012;380:29-36.
22. Roth EM, McKenney JM, Hanotin C, et al. Atorvastatin with or without an antibody to PCSK9 in primary hypercholesterolemia. N Engl J Med 2012;367:1891-900.

23. Kereiakes DJ, Robinson JG, Cannon CP, et al. Efficacy and safety of the proprotein convertase subtilisin/kexin type 9 inhibitor alirocumab among high cardiovascular risk patients on maximally tolerated statin therapy: the ODYSSEY COMBO I study. Am Heart J 2015;169: 906-15.

24. Cannon CP, Cariou B, Blom D, et al. Efficacy and safety of alirocumab in high cardiovascular risk patients with inadequately controlled hypercholesterolaemia on maximally tolerated doses of statins: the ODYSSEY COMBO II randomized controlled trial. Eur Heart J 2015;36:1186-94.

25. Roth EM, Taskinen MR, Ginsberg HN, et al. Monotherapy with the PCSK9 inhibitor alirocumab versus ezetimibe in patients with hypercholesterolemia: results of a 24 week, double-blind, randomized phase 3 trial. Int J Cardiol 2014;176:55-61.

26. Kastelein JJ, Ginsberg HN, Langslet G, et al. ODYSSEY FH I and FH II: 78 week results with alirocumab treatment in 735 patients with heterozygous familial hypercholesterolaemia. Eur Heart J 2015;36: 2996-3003.

27. Bays H, Gaudet D, Weiss R, et al. Alirocumab as addon to atorvastatin versus other lipid treatment strategies: ODYSSEY OPTIONS I randomized trial. J Clin Endocrinol Metab 2015;100:3140-8.

28. Farnier M, Jones P, Severance R, et al. Efficacy and safety of adding alirocumab to rosuvastatin versus adding ezetimibe or doubling the rosuvastatin dose in high cardiovascular-risk patients: the ODYSSEY OPTIONS II randomized trial. Atherosclerosis 2016;244:138-46.

29. Ginsberg HN, Rader DJ, Raal FJ, et al. Efficacy and safety of alirocumab in patients with heterozygous familial hypercholesterolemia and LDL-C of $160 \mathrm{mg} / \mathrm{dl}$ or higher. Cardiovasc Drugs Ther 2016;30:473-83.

30. Moriarty PM, Thompson PD, Cannon CP, et al. Efficacy and safety of alirocumab vs ezetimibe in statin-intolerant patients, with a statin rechallenge arm: the ODYSSEY ALTERNATIVE randomized trial. J Clin Lipidol 2015;9:758-69.

31. Roth EM, Moriarty PM, Bergeron J, et al. A phase III randomized trial evaluating alirocumab $300 \mathrm{mg}$ every 4 weeks as monotherapy or add-on to statin: ODYSSEY CHOICE I. Atherosclerosis 2016;254:254-62.

32. Stroes E, Guyton JR, Lepor N, et al. Efficacy and safety of alirocumab $150 \mathrm{mg}$ every 4 weeks in patients with hypercholesterolemia not on statin therapy: the ODYSSEY CHOICE II study. J Am Heart Assoc 2016;5:9.

33. Moriarty PM, Parhofer KG, Babirak SP, et al. Alirocumab in patients with heterozygous familial hypercholesterolaemia undergoing lipoprotein apheresis: the ODYSSEY ESCAPE trial. Eur Heart J 2016;37:3588-95.

34. Teramoto T, Kobayashi M, Tasaki H, et al. Efficacy and safety of alirocumab in Japanese patients with heterozygous familial hypercholesterolemia or at high cardiovascular risk with hypercholesterolemia not adequately controlled with statins-ODYSSEY JAPAN 
randomized controlled trial. Circ J 2016;80:1980-7.

35. Koh KK, Nam CW, Chao TH, et al. A randomized trial evaluating the efficacy and safety of alirocumab in South Korea and Taiwan (ODYSSEY KT). J Clin Lipidol 2018;12:162-72.

36. El Shahawy M, Cannon CP, Blom DJ, et al. Efficacy and safety of alirocumab versus ezetimibe over 2 years (from ODYSSEY COMBO II). Am J Cardiol 2017;120:931-9.

37. Schwartz GG, Bessac L, Berdan LG, et al. Effect of alirocumab, a monoclonal antibody to PCSK9, on longterm cardiovascular outcomes following acute coronary syndromes: rationale and design of the ODYSSEY Outcomes trial. Am Heart J 2014;168:682-9.

38. Farnier M. Alirocumab for the treatment of hyperlipidemia in high-risk patients: an updated review. Expert Rev Cardiovasc Ther 2017;15:923-32.

39. Steg PG, Kumbhani DJ. Evaluation of cardiovascular outcomes after an acute coronary syndrome during treatment with alirocumab - ODYSSEY OUTCOMES. American College of Cardiology. 2018. Available from: http://www.acc.org/latest-in-cardiology/clinical-trials/ 2018/03/09/08/02/odyssey-outcomes Accessed: 23 April 2018.

40. Blom DJ, Hala T, Bolognese M, et al. A 52-week placebo-controlled trial of evolocumab in hyperlipidemia. N Engl J Med 2014;370:1809-19.

41. Koren MJ, Lundqvist P, Bolognese M, et al. Anti-PCSK9 monotherapy for hypercholesterolemia: the MENDEL-2 randomized, controlled phase III clinical trial of evolocumab. J Am Coll Cardiol 2014;63:2531-40.

42. Stroes E, Colquhoun D, Sullivan D, et al. Anti-PCSK9 antibody effectively lowers cholesterol in patients with statin intolerance: the GAUSS-2 randomized, placebocontrolled phase 3 clinical trial of evolocumab. J Am Coll Cardiol 2014;63:2541-8.

43. Raal FJ, Honarpour N, Blom DJ, et al. Inhibition of PCSK9 with evolocumab in homozygous familial hypercholesterolaemia (TESLA Part B): a randomised, double-blind, placebo-controlled trial. Lancet 2015;385:341-50.

44. Raal FJ, Stein EA, Dufour R, et al. PCSK9 inhibition with evolocumab (AMG 145) in heterozygous familial hypercholesterolaemia (RUTHERFORD-2): a randomised, double-blind, placebo-controlled trial. Lancet 2015;385:331-40.

45. Robinson JG, Nedergaard BS, Rogers WJ, et al. Effect of evolocumab or ezetimibe added to moderate- or highintensity statin therapy on LDL-C lowering in patients with hypercholesterolemia: the LAPLACE-2 randomized clinical trial. JAMA 2014;311:1870-82.

46. Sabatine MS, Giugliano RP, Wiviott SD, et al. Efficacy and safety of evolocumab in reducing lipids and cardiovascular events. N Engl J Med 2015;372:1500-9.

47. Nicholls SJ, Puri R, Anderson T, et al. Effect of evolocumab on progression of coronary disease in statin-treated patients: the GLAGOV randomized clinical trial. JAMA 2016;316:2373-84.

48. Sabatine MS, Leiter LA, Wiviott SD, et al. Cardiovascular safety and efficacy of the PCSK9 inhibitor evolocumab in patients with and without diabetes and the effect of evolocumab on glycaemia and risk of new-onset diabetes: a prespecified analysis of the
FOURIER randomised controlled trial. Lancet Diabetes Endocrinol 2017;5:941-50.

49. Raal FJ, Hovingh GK, Blom D, et al. Long-term treatment with evolocumab added to conventional drug therapy, with or without apheresis, in patients with homozygous familial hypercholesterolaemia: an interim subset analysis of the open-label TAUSSIG study. Lancet Diabetes Endocrinol 2017;5:280-90.

50. Davis KA, Miyares MA. Lomitapide: a novel agent for the treatment of homozygous familial hypercholesterolemia. Am J Health Syst Pharm 2014;71:1001-8.

51. Cuchel M, Meagher EA, du Toit Theron H, et al. Efficacy and safety of a microsomal triglyceride transfer protein inhibitor in patients with homozygous familial hypercholesterolaemia: a single-arm, open-label, phase 3 study. Lancet 2013;381:40-6.

52. Blom DJ, Averna MR, Meagher EA, et al. Long-term efficacy and safety of the microsomal triglyceride transfer protein inhibitor lomitapide in patients with homozygous familial hypercholesterolemia. Circulation 2017;136:332-5

53. Vogt A, Parhofer KG. The potential of mipomersen, an ApoB synthesis inhibitor, to reduce necessity for LDLapheresis in patients with heterozygous familial hypercholesterolemia and coronary artery disease. Expert Opin Pharmacother 2013;14:691-7.

54. Santos RD, Duell PB, East C, et al. Long-term efficacy and safety of mipomersen in patients with familial hypercholesterolaemia: 2-year interim results of an open-label extension. Eur Heart J 2013;36:566-75.

55. Akdim F, Stroes ES, Sijbrands EJ, et al. Efficacy and safety of mipomersen, an antisense inhibitor of apolipoprotein B, in hypercholesterolemic subjects receiving stable statin therapy. J Am Coll Cardiol 2010;55:1611-8

56. Akdim F, Visser ME, Tribble DL, et al. Effect of mipomersen, an apolipoprotein B synthesis inhibitor, on low-density lipoprotein cholesterol in patients with familial hypercholesterolemia. Am J Cardiol 2010;105:1413-9.

57. Raal FJ, Santos RD, Blom DJ, et al. Mipomersen, an apolipoprotein B synthesis inhibitor, for lowering of LDL cholesterol concentrations in patients with homozygous familial hypercholesterolaemia: a randomised, double-blind, placebo-controlled trial. Lancet 2010;375:998-1006.

58. McGowan MP, Tardif JC, Ceska R, et al. Randomized, placebo-controlled trial of mipomersen in patients with severe hypercholesterolemia receiving maximally tolerated lipid-lowering therapy. PLoS One 2012; 7:e49006.

59. Thomas GS, Cromwell WC, Ali S, et al. Mipomersen, an apolipoprotein B synthesis inhibitor, reduces atherogenic lipoproteins in patients with severe hypercholesterolemia at high cardiovascular risk: a randomized, double-blind, placebo-controlled trial. J Am Coll Cardiol 2013;62:2178-84.

60. Visser ME, Wagener G, Baker BF, et al. Mipomersen, an apolipoprotein B synthesis inhibitor, lowers lowdensity lipoprotein cholesterol in high-risk statin-intolerant patients: a randomized, double-blind, placebo-controlled trial. Eur Heart J 2012;33:1142-9. 